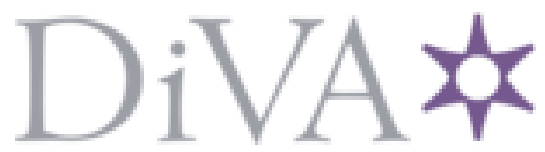

http://www.diva-portal.org

This is the published version of a paper published in Nordic Pulp \& Paper Research Journal.

Citation for the original published paper (version of record):

Nyflött, Å., Axrup, L., Gunilla, C., Järnström, L., Lestelius, M. et al. (2015)

Influence of kaolin addition on the dynamics of oxygen mass transport in polyvinyl alcohol dispersion coatings.

Nordic Pulp \& Paper Research Journal, 30(3): 385-392

http://dx.doi.org/10.3183/NPPRJ-2015-30-03-p385-392

Access to the published version may require subscription.

N.B. When citing this work, cite the original published paper.

Permanent link to this version:

http://urn.kb.se/resolve?urn=urn:nbn:se:kau:diva-34457 


\title{
Influence of kaolin addition on the dynamics of oxygen mass transport in polyvinyl alcohol dispersion coatings
}

\author{
Åsa Nyflött, Lars Axrup, Gunilla Carlsson, Lars Järnström, Magnus Lestelius, Ellen Moons and Torbjörn Wahlström
}

KEYWORDS: Barrier coating, Kaolin, Polyvinyl alcohol, Permeability, Dynamic mass transport

SUMMARY: The permeability of dispersion barriers produced from polyvinyl alcohol $(\mathrm{PVOH})$ and kaolin clay blends coated onto polymeric supports has been studied by employing two different measurement methods: the oxygen transmission rate (OTR) and the ambient oxygen ingress rate (AOIR). Coatings with different thicknesses and kaolin contents were studied. Structural information of the dispersion-barrier coatings was obtained by Fourier transform infrared spectroscopy (FTIR) spectroscopy and scanning electron microscopy (SEM). These results showed that the kaolin content influences both the orientation of the kaolin and the degree of crystallinity of the PVOH coating. Increased kaolin content increased the alignment of the kaolin platelets to the basal plane of the coating. Higher kaolin content was accompanied by higher degree of crystallinity of the PVOH. The barrier thickness proved to be less important in the early stages of the mass transport process, whereas it had a significant influence on the steady-state permeability. The results from this study demonstrate the need for better understanding of how permeability is influenced by (chemical and physical) structure.

\section{ADDRESSES OF THE AUTHORS:}

Åsa Nyflött (asa.nyflott@kau.se), Gunilla Carlsson (gunilla.carlsson@kau.se), Lars Järnström (lars.jarnstrom@kau.se) and Magnus Lestelius (magnus.lestelius@kau.se): Department of Engineering and Chemical Sciences, Karlstad University, SE-651 88 Karlstad, Sweden. Ellen Moons (ellen.moons@kau.se): Department of Engineering and Physics, Karlstad University, SE-651 88 Karlstad, Sweden. Åsa Nyflött, Torbjörn Wahlström (torbjorn.wahlstrom@storaenso.com) and Lars Axrup (lars.axrup@storaenso.com): Stora Enso, Karlstad Research Centre, SE-650 09 Karlstad, Sweden

\section{Corresponding author: Åsa Nyflött}

Food packages require barrier properties to ensure food safety, quality, and to minimize spoilage; furthermore, the package should also be easy to handle. The barriers should have the ability to regulate moisture, grease, and gas transport. Oxygen may be detrimental to the quality of packed food, especially if the food contains lipids (Lopez-Cervantes et al. 2003). Lipid oxidation is one of the most common causes of deterioration of food quality (Huis in 't Veld 1996).

Currently utilized oxygen barriers are mostly based on non-renewable materials, such as polyvinyl alcohol $(\mathrm{PVOH})$, or ethylene vinyl alcohol $(\mathrm{EVOH})$, and these are occasionally filled with clay particles. Different techniques can be employed to coat the carton board with the barrier, such as lamination, extrusion, and dispersion coating. The performance of the oxygen barrier is dependent on the processing conditions, the properties of the utilized polymer, and whether or not fillers are included (Johansson et al. 2012). The orientation of the fillers is of importance and it depends on the type of the filler used (Bollström et al. 2013).

The mass transport of oxygen through a barrier is affected by the polymer characteristics as well as the free volume, porosity, and voids in the barrier (Crank 1979). The diffusion and solubility of oxygen can be controlled by the polymer properties and by reinforcing fillers. The function of the clay is to increase the tortuosity or the pathway for the diffusant (Nielsen 1967). Polymers, such as polylactic acid (PLA), poly(hydroxyalkanoates) (PHA), poly(caprolactones) (PCL) or poly(hydroxylbutyrate) (PHB) have shown an improvement in the barrier performance when filled with nanoclay if the loading level is less than 5 weight percent. At higher loading levels, no further enhancement of the barrier performance was detected. The nanoclay also affected the crystallinity of the polymer (Sanchez-Garcia et al. 2010 Strawhecker, Manias 2000, Gaume et al. 2012, Sapalidis et al. 2012). Poly(propylene) (PP) filled with nanoclay displayed an improved barrier performance and the morphology was also affected (Zehetmeyer et al. 2012). The same behaviour has been reported for PVOH mixed with nanoclay (Strawhecker, Manias 2000, Yu et al. 2003, Johansson, Clegg 2015) and EVOH (Cabedo et al. 2004).

The oxygen permeability can be measured with different techniques. The most commonly used is the oxygen transmission rate (OTR) method. Ambient oxygen ingress rate (AOIR) is an alternative method for monitoring the mass transport process, especially in the initial stage. The main difference in test conditions between these two techniques is the partial pressure difference across the samples, as oxygen is transported away from the cell for the OTR method but not for the AOIR method, although they start with the same partial pressure. Still, both methods can determine the steadystate permeability, whereas the permeability calculated from the AOIR also shows the dynamics of the mass transport with a much higher time resolution.

The overall aim of the present work is to study the relation between the structure and composition of dispersion-barrier coatings in relation to their oxygen permeability, which is assessed by studying the dynamics of the mass transport through the coatings. To that end, barrier dispersion coatings of $\mathrm{PVOH}$ and kaolin clay were prepared onto a polymeric substrate polyethylene terephthalate (PET) using a laboratory rod coater. Oxygen transport properties were assessed using the OTR and AOIR methods. The AOIR method was used in order to study the initial stage, which can be linked to the properties of the sample, and to compare this method with the OTR technique. The coating thickness and the 
kaolin content were varied, to assess any potential influence on the physical properties of both polymer and clay. The cross-section of the barrier coatings were imaged by scanning electron microscopy (SEM) and the orientation of kaolin and the crystallinity of PVOH were characterized by Fourier transform infrared spectroscopy (FTIR) spectroscopy.

\section{Materials and Methods}

\section{Materials}

Waterborne barrier dispersants were prepared of PVOH (Mowiol 15-99 from Kuraray, Frankfurt, Germany) and kaolin (Barrisurf LX from IMERYS, Cornwall, UK). The kaolin particles were received with pre-treatment by sodium polyacrylate (NaPAA). Additional sodium hydroxide $(\mathrm{NaOH})$ was purchased from Merck (Darmstadt, Germany) with purity 99.9\%. Magnesium nitrate $\left(\mathrm{Mg}\left(\mathrm{NO}_{3}^{-}\right)_{2}\right)$ was obtained from Merck (Darmstadt, Germany) with purity 99.9\%. PET sheets were purchased from $\mathrm{HiFi}$ Industrial Films (Hertfordshire, UK) and had a nominal thickness of $23 \mu \mathrm{m}$. The PET sheets served as coating substrates due to the even sheet thickness, which produced smooth barrier coatings. Another reason was the surface energy of PET $\left(43 \mathrm{~mJ} / \mathrm{m}^{2}\right)$ and PVOH $\left(49 \mathrm{~mJ} / \mathrm{m}^{2}\right)$, which resulted in a high adhesion strength of the coating (Lee 1968).

\section{Preparation of PVOH and kaolin dispersions}

$\mathrm{PVOH}$ was dissolved in tap water at $95^{\circ} \mathrm{C}$ under gentle stirring for $1.5 \mathrm{~h}$. The polymer solution was thereafter cooled to room temperature before film preparation. The concentration of the final PVOH solution was $16 \mathrm{wt} \%$ in water, and the $\mathrm{pH}$ and conductivity were 5.8 and $0.12 \mathrm{mS} \mathrm{cm}^{-1}$, respectively. The kaolin was dispersed in water during stirring to a concentration of $60 \mathrm{wt} \%$ and afterwards diluted to $10 \mathrm{wt} \%, 5 \mathrm{wt} \%, 1 \mathrm{wt} \%, 0.6 \mathrm{wt} \%$ and $0.1 \mathrm{wt} \%$. The $\mathrm{pH}$ and the conductivity of the kaolin suspension of $60 \mathrm{wt} \%$ were 6.4 and $1.6 \mathrm{mS} \mathrm{cm}$, respectively.

\section{Preparation of barrier coatings of PVOH and kaolin}

Since the kaolin performance, according to the supplier, is highest in neutral $\mathrm{pH}$, the $\mathrm{PVOH}$ solution and kaolin dispersion were both $\mathrm{pH}$-adjusted to $\mathrm{pH} 7.3$ by addition of $\mathrm{NaOH}$. The PVOH solution and the kaolin dispersion were mixed in 1:1 ratio with respect to wet weight. In the dried state, the dispersions have the weight proportions PVOH:kaolin 62:38, 84.2:15.8, 94.2:5.8, 96.9:3.1 and 99.3:0.7 and $\mathrm{PVOH} 100 \mathrm{wt} \%$, referred to hereafter as PVOHk38, PVOHk15.8, PVOHk5.8, PVOHk3.1 PVOHk0.7 and PVOH, respectively. The dispersions were coated onto PET sheets by a bench coater, (K202 Control Coater, RK Print Coat Instruments Ltd., Royston, UK) using a wire-wound cylindrical rod (nos. 3 and 8) and subsequently dried at $105^{\circ} \mathrm{C}$ for $3 \mathrm{~min}$. The barrier coatings were made with two different rods, which gave nominal thicknesses of the wet films of 24 and $100 \mu \mathrm{m}$.

The thickness of the dry barrier coatings was measured with a mechanical profilometer (STFI thickness profilemeter, TJT-Teknik AB, Järfälla, Sweden). Table 1 shows the thickness values of the dry barrier coatings. The thickness of the PET sheet was found to be $22 \mu \mathrm{m} \pm 0.1 \mu \mathrm{m}$.

\section{Methods for barrier characterisation}

Two methods were used to measure the oxygen permeability through the barrier: the oxygen transmission rate (OTR) (Ox-Tran 2/21 MOCON, Minneapolis, US) and the ambient oxygen ingress rate (AOIR) (PermMate, Systech, Illinois, US). The OTR was measured according to ASTM D3985 where air was used as permeant (oxygen concentration 20.9\%). The OTR measurements were performed on coated PET sheets with the barrier towards the centre of the cell. The exposed area was $50 \mathrm{~cm}^{2}$. The cells were flushed with nitrogen of a partial pressure of approximately $200 \mathrm{mbar}$ for $6 \mathrm{~min}$. The measurements were carried out in $23^{\circ} \mathrm{C}$ and at $50 \% \mathrm{RH}$. The acquisition time of each data point was $2 \mathrm{~min}$ and the measurement continued until a stable level was reached after about $2 \mathrm{~h}$. The first measurement of OTR was made after approximately $10 \mathrm{~min}$. With this method the steady state permeability was determined. The dynamics of the oxygen mass transport was monitored by the AOIR method. This method measures the increase in oxygen concentration over time in, as in this case, a sample package or cell. In-house customized sample cells were produced for the AOIR method, see Fig 1. The barrier was mounted between the flanges, and the climate inside the cell was controlled by a $\left(\mathrm{Mg}\left(\mathrm{NO}_{3}^{-}\right)_{2}\right)$ salt solution. The concentration increase was measured by the sensor in the PermMate equipment by inserting a needle in the inlet/outlet. It has been shown elsewhere that the AOIR can be used to calculate the OTR (Larsen, Kohler et al. 2000). The measurement of the oxygen concentration increase is used to calculate the permeability, $P$ :

$$
P=\frac{V \cdot\left(p_{f}-p_{i}\right) \cdot \tau}{p_{a t m} \cdot\left(t_{f}-t_{i}\right)}=\frac{V \cdot\left(c_{f}-c_{i}\right) \cdot R \cdot T \cdot \tau}{V_{\text {gas }(S T P)} \cdot p_{a t m} \cdot A \cdot\left(t_{f}-t_{i}\right)}
$$

where $V$ is the volume of the sample cell (our cells have the volume $330 \mathrm{ml}$ ), $\tau$ is the thickness of the sample, $c_{i}$ and $c_{f}$ is initial and final the concentration, respectively, $p_{a t m}$ is the atmospheric pressure, $T$ is the temperature, and $t_{i}$ and $t_{f}$ are the initial and final time, respectively.

The AOIR measurements were made in a controlled climate at $23{ }^{\circ} \mathrm{C}$ and $50 \% \mathrm{RH}$. Inside the sample cell, the $\mathrm{RH}$ was controlled by a saturated solution of $\mathrm{Mg}\left(\mathrm{NO}_{3}^{-}\right)_{2}$. The sample cells were flushed on one side with nitrogen to lower the oxygen concentration to about $1 \%$, with a differential pressure of approximately $200 \mathrm{mbar}$, which took approximately $7 \mathrm{~min}$.

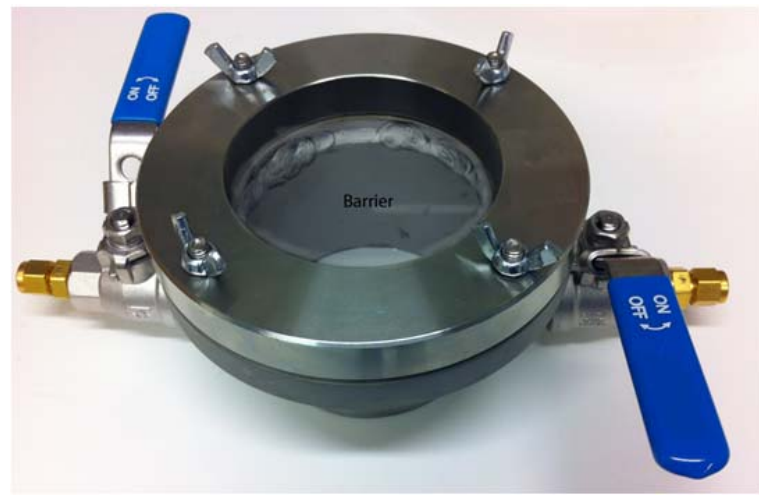

Fig 1 - Image of the sample cell used for the AOIR method 
When necessary, the sample cell was refilled with nitrogen in order to keep the pressure constant. Measurement data was collected after 1, 3, 5, 7, 9, 20, and $30 \mathrm{~min}$ in order to capture the initial phenomena and thereafter once a day for a period of 1 to 4 days, for comparison to the OTR method. The oxygen concentration was re-calculated in order to take into account the refilling of nitrogen by assuming that the refilled volume has the same oxygen concentration as the rest of the volume. An off-set of the concentration of oxygen in the sample cell at the starting time was used to make them comparable.

\section{Methods for structural characterisation}

The degree of crystallinity of the polymer and orientation of the clay can be studied by FTIR. The FTIR spectra were collected with a Thermo Nicolet FTIR Nexus (Madison, US) in transmission mode. The spectra were processed with the OMNIC 6.0a software. Normalisation of the FTIR curve was done in the studied region using the OMNIC software. The samples were peeled off from the PET substrate. The samples without PET substrate were kept in air while collecting the spectra with 64 repeated scans and a resolution of $0.5 \mathrm{~cm}^{-1}$. Kaolin has peaks in the $3600-3700 \mathrm{~cm}^{-1}$ region, which represent dipole oscillation of the $\mathrm{OH}$ bonds (for peak assignment, see Table 2). In this region, kaolin has four peaks of which three $\left(3670,3652,3620 \mathrm{~cm}^{-1}\right)$ represent bonds oriented with a shallow angle to the basal plane of the kaolin platelets while one $\left(3695 \mathrm{~cm}^{-1}\right)$ represents a perpendicularly oriented bond (Farmer 1964, Elton et al. 1999). The kaolin orientation factor, $\kappa$, can be calculated from the ratio of the peak intensity at $3695 \mathrm{~cm}^{-1}$ over the peak intensity at $3620 \mathrm{~cm}^{-1}$ (Elton et al. 1999).

$$
\kappa=\frac{\text { peak intensity } 3695 \mathrm{~cm}^{-1}}{\text { peak intensity } 3620 \mathrm{~cm}^{-1}}
$$

Low $\kappa$ is interpreted as the basal plane of the kaolin platelets is oriented perpendicular to the IR-beam, which means greater alignment with the substrate. The ratio of crystalline to amorphous regions of the $\mathrm{PVOH}$ can be calculated from the FTIR peaks. Both the crystalline and amorphous regions in the $\mathrm{PVOH}$ can be studied by the C-O stretch in the $1090-1150 \mathrm{~cm}-1$ region, for peak assignment see Table 2 (Peppas 1977, Kozlov et al. 2003, Tretinnikov, Zagorskaya 2012). The degree of crystallinity, $\alpha$, can be calculated from the ratio of the peak intensity in the crystalline region (1140-1145 $\left.\mathrm{cm}^{-1}\right)$ to the peak intensity in the amorphous region (1090$1096 \mathrm{~cm}^{-1}$ ) (Tretinnikov, Zagorskaya 2012):

$$
\alpha(\%)=-13.1+89.5 \cdot \frac{\text { crystalline peak intensity }}{\text { amorphous peak intensity }}
$$

The SEM images were captured in high vacuum $\left(10^{-5}-\right.$ $10^{-6}$ mbar), (FEI Quanta 200, FEI, Brno, Czech Republic) using the Quanta 2.4 software. The detector was a solid state detector (SSD), which detects backscattered electrons. The coated films were placed between two glass plates (Bellco Cover-Slips) and the cross-sections were prepared with an ion-beam cutter (Hitachi IM4000), sputtering the samples with argon ions for $7 \mathrm{~h}$ (acceleration voltage $3 \mathrm{kV}$, discharge voltage $1.5 \mathrm{kV}$, gas flow $0.08 \mathrm{~cm}^{3} \mathrm{~min}^{-1}$ ). The cross-sections were sputter coated with carbon before capturing the images. The images were captured with a magnification of 10000 and acceleration voltage of $12.5 \mathrm{kV}$, except for the PVOHk $38_{t=5.9}$ and PVOHk38 $8_{t=10.7}$, which were captured with acceleration voltage of $15 \mathrm{kV}$. The same films were used for the SEM and the OTR measurements, i.e. PVOH, PVOHk5.8 and PVOHk38.

\section{Results and discussion}

Barrier coatings with different kaolin contents $(0.7,3.1$, $5.8,15.8$ and $38 \mathrm{wt} \%$ ) were produced with two different wet thicknesses, Table 1. The permeability measured with the OTR and AOIR methods, was compared for PVOH, PVOHk5.8 and PVOHk38. All samples were measured with the AOIR method. Some samples were selected for measurement by the OTR method as well, in order to assess our setup to that used in previous studies (Larsen et al. 2000).

Table 1 - Mean values for thicknesses, OTR and AOIR values of the barrier layers are shown in the columns 2-4 for the various samples (column 1). Calculated mean values orientation factor, $\kappa$, and $\alpha$ crystalline factor from FTIR data are shown in columns 5-6. The degree of crystallinity, a, of PVOH is calculated according to Eq 3.The mean values are based on 6 samples the $95 \%$ confidence intervals are also shown. Note that the same samples were used for both OTR and AOIR methods and were measured at $50 \% \mathrm{RH}$

\begin{tabular}{|c|c|c|c|c|c|}
\hline Sample & $\begin{array}{l}\text { Thickness } \\
{[\mu \mathrm{m}]}\end{array}$ & $\begin{array}{r}\text { OTR permeability } \\
{[\mathrm{ml} \mu \mathrm{m} \mathrm{n}}\end{array}$ & $\begin{array}{l}\text { AOIR permeability } \\
\left.\text { day }^{-1} \mathrm{~atm}^{-1}\right]\end{array}$ & $\kappa$ & $\begin{array}{l}\alpha \\
{[\%]}\end{array}$ \\
\hline $\begin{array}{l}\text { PVOH }_{\mathrm{t}=4.4} \\
\text { PVOHk0.7t=3.7 } \\
\text { PVOHk3.1t=3.7 } \\
\text { PVOHk5.8t=5.2 } \\
\text { PVOHk15.8t=2.5 } \\
\text { PVOHk38t=5.9 }\end{array}$ & $\begin{array}{l}4.4 \pm 0.2 \\
3.7 \pm 0.1 \\
3.7 \pm 0.1 \\
5.2 \pm 0.2 \\
2.5 \pm 0.1 \\
5.9 \pm 0.2\end{array}$ & $\begin{array}{l}1.2 \pm 0.7 \\
- \\
- \\
1.1 \pm 0.3 \\
- \\
0.7 \pm 0.3\end{array}$ & $\begin{array}{l}1.8 \pm 1.5 \\
1.5 \pm 0.7 \\
1.8 \pm 1.6 \\
1.4 \pm 1.9 \\
1.3 \pm 0.4 \\
0.9 \pm 0.7\end{array}$ & $\begin{array}{l}- \\
0.77 \pm 0.03 \\
0.78 \pm 0.03 \\
0.65 \pm 0.01 \\
0.90 \pm 0.03 \\
0.76 \pm 0.01\end{array}$ & $\begin{array}{l}48 \pm 4.9 \\
50 \pm 0.3 \\
43 \pm 0.5 \\
40 \pm 0.5 \\
45 \pm 0.5 \\
40 \pm 9.0\end{array}$ \\
\hline $\begin{array}{l}\text { PVOH }_{\mathrm{t}=10.9} \\
\text { PVOHk0.7t=6.4 } \\
\text { PVOHk3.1t=7.2 } \\
\text { PVOHk5.8t=11.1 } \\
\text { PVOHk15.8t=7.4 } \\
\text { PVOHk38t=10.7 }\end{array}$ & $\begin{array}{l}10.9 \pm 0.3 \\
6.4 \pm 0.1 \\
7.2 \pm 0.1 \\
11.1 \pm 0.2 \\
7.4 \pm 0.1 \\
10.7 \pm 0.2\end{array}$ & $\begin{array}{l}0.8 \pm 0.5 \\
- \\
- \\
0.9 \pm 0.5 \\
- \\
3.1 \pm 0.6\end{array}$ & $\begin{array}{l}0.8 \pm 0.4 \\
1.1 \pm 0.4 \\
1.2 \pm 0.2 \\
1.1 \pm 1.2 \\
1.6 \pm 0.4 \\
2.7 \pm 1.3\end{array}$ & $\begin{array}{l} \\
0.47 \pm 0.03 \\
0.68 \pm 0.03 \\
0.65 \pm 0.01 \\
0.66 \pm 0.03 \\
0.71 \pm 0.01\end{array}$ & $\begin{array}{l}44 \pm 4.8 \\
35 \pm 0.5 \\
25 \pm 1.2 \\
37 \pm 0.7 \\
26 \pm 1.5 \\
26 \pm 0.3\end{array}$ \\
\hline
\end{tabular}
and $23^{\circ} \mathrm{C}$. 
For the comparison the same samples was used in both methods (Table 1). The AOIR and OTR permeability results are comparable (Table 1), which confirmed earlier findings (Larsen et al. 2000). The PET sheet had a permeability of $890 \pm 10 \mathrm{ml} \mu \mathrm{m} \mathrm{m}^{-2}$ day $^{-1}$ atm $^{-1}$ which is significantly higher than that of the barrier materials and is therefore not influencing the results. The trends for the permeability of the films showed a minor reduction for the AOIR results with increasing kaolin content up to $5.8 \mathrm{wt} \%$. For the thicker barriers, the barrier with $15.8 \mathrm{wt} \%$ shows an increase in permeability. This is linked to the structure of the barriers, i.e. the kaolin causes pores in the polymer matrix (Moldrup et al. 2001). Some samples show high error margins $\left(\mathrm{PVOH}_{\mathrm{t}=4.4}\right.$, PVOHk3.1 $1_{\mathrm{t}=3.7}, \quad$ PVOHk5.8 $8_{\mathrm{t}=5.2}, \quad$ PVOHk38 $8_{\mathrm{t}=5.9}$ and PVOHk5.8 $8_{t=11.1}$ ), which is probably due to local variations in thickness of the material. In particular, the sample PVOHk5.8, of thicknesses 5.2 and $11.1 \mu \mathrm{m}$, showed confidence intervals that exceeded the mean value. It is our belief that these samples showed greater thickness variations although thickness measurements do not indicate anything out of the ordinary. The thickness, the kaolin orientation and the degree of crystallinity in PVOH are presented with confidence intervals.

Fig 2 depicts the oxygen concentration versus time measured by the AOIR method. The first $30 \mathrm{~min}$ is presented in Fig 2a, while the period up to 4 days is presented in Fig 2b. During the initial time (0-30 min) the oxygen concentration is lower than that at steady state (Fig 2b) and interesting features of the dynamic mass transport were found. The AOIR permeability results show that while the initial permeability is higher for the thinner barrier films $\left(\mathrm{PVOH}_{\mathrm{t}=4.4}, \mathrm{PVOHk}_{0.73_{\mathrm{t}=3.7}}\right.$

PVOHk3.1 $1_{\mathrm{t}=3.7}$ and PVOHk38 $\left.8_{\mathrm{t}=5.9}\right)$, than for the corresponding thicker films $\left(\mathrm{PVOH}_{\mathrm{t}=10.9} \mathrm{PVOHk} 0.7_{\mathrm{t}=6.4}\right.$ PVOHk3.1 $1_{t=7.2}$ and PVOHk38 $\left.8_{t=10.7}\right)$, the steady-state permeability is lower for the thinner samples. The AOIR permeability is lower initially for the thinner samples (PVOHk5.8 $\mathrm{t}_{\mathrm{t}=5.2}$ and PVOHk15.8 $\mathrm{t}=2.5$ ), compared to the corresponding thicker sample (PVOHk5.8 $8_{\mathrm{t}=11.1}$ and

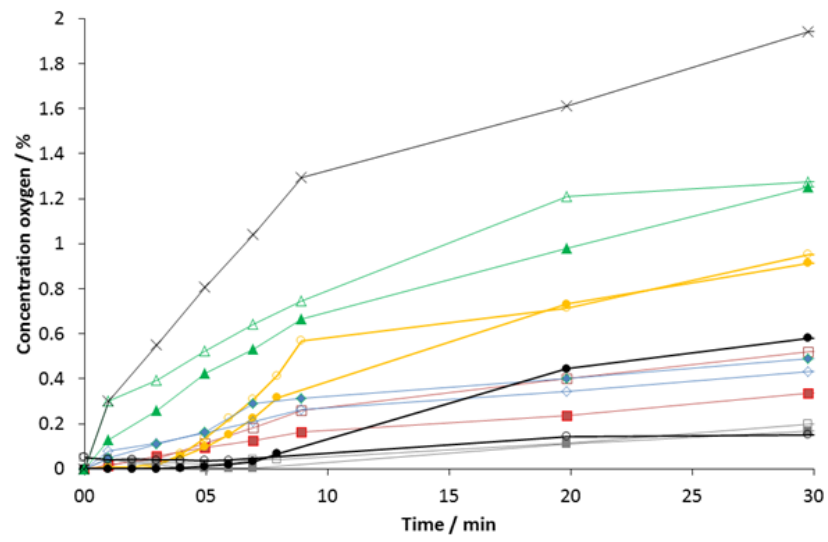

a)

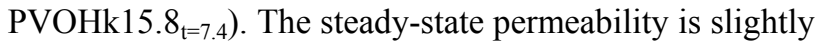
higher for the thinner sample. The early-stage AOIR permeability can give information about cavities, less dense regions, or structurally different regions in the samples, where the oxygen could reside in a period before contributing to the steady state permeability. Lag time is captured in the of the early-stage AOIR measurement, which is influenced of the barrier structure and properties of the polymer. The early-stage AOIR permeability shows different velocities of oxygen mass transport, Fig 2a. The lag time is dependent on the thickness of the sample as well as the diffusion (Crank 1979). High diffusion coefficients will have a low lag time. The lag time is of importance, especially for samples with low diffusion coefficients, as the samples in this study, see Fig 2. The films are flushed with nitrogen, which removes the oxygen molecules that are not trapped. However, oxygen molecules that are trapped in the material can influence the measurements, which can be seen as a step in the initial measurements, (see Fig 2 a curve PVOHk0.7 thick). The oxygen molecules can be trapped due to the tortuosity introduced by polymer crystallinity and kaolin platelets. The FTIR spectra of the some barriers (PVOH, PVOHk5.8 and PVOHk38) are presented in Fig 3, and the peaks related to the kaolin in the coating layers are show. For the complete peak assignment, see Table 2. As can be seen in Fig 3, the barrier made of pure $\mathrm{PVOH}$ did not display any peaks in the region for determining the kaolin orientation. The $\mathrm{OH}$-stretch of $\mathrm{PVOH}$ is found in another region of the FTIR spectrum (at $3500-3200 \mathrm{~cm}^{-1}$ ), and is not presented here. Fig 3 shows the normalized peaks in the studied region.

The orientation factor, $\kappa$, was calculated from the peak intensity at $3695 \mathrm{~cm}^{-1}$ and $3620 \mathrm{~cm}^{-1}, E q 2$. The results in Table 1 reveal a slight higher $\kappa$ in the thin films compared to the thick films, i.e. clay platelets are less aligned to the substrate in the thin films than in the thick films.

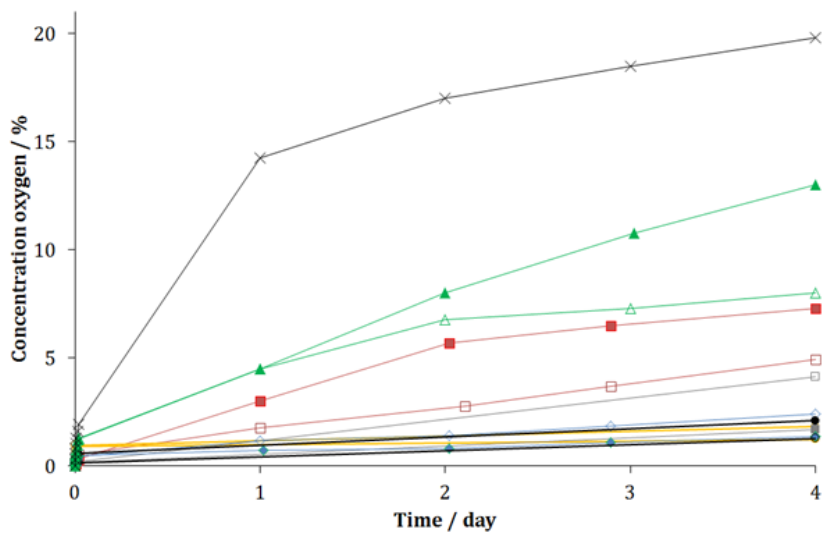

b)

Fig 2 - AOIR measurements of the oxygen concentration (\%) versus time a) for the first 30 min and b) up to 4 days. The data points are the means values of 6 measurements. The black cross represent the PET film $(X)$, filled red square symbols $P V O H t=4.4(\square)$,

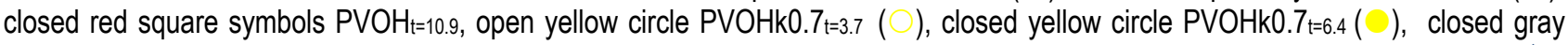

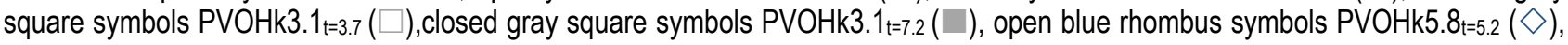
closed blue rhombus symbols PVOHk5.8t=11.1 $(\bullet)$, open black circle PVOHk15.8t=2.5 (O) closed black circle PVOHk15.8t=7.4 $(\bullet), 0 p e n$

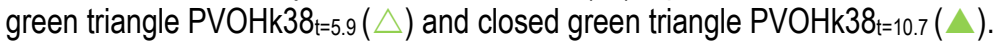




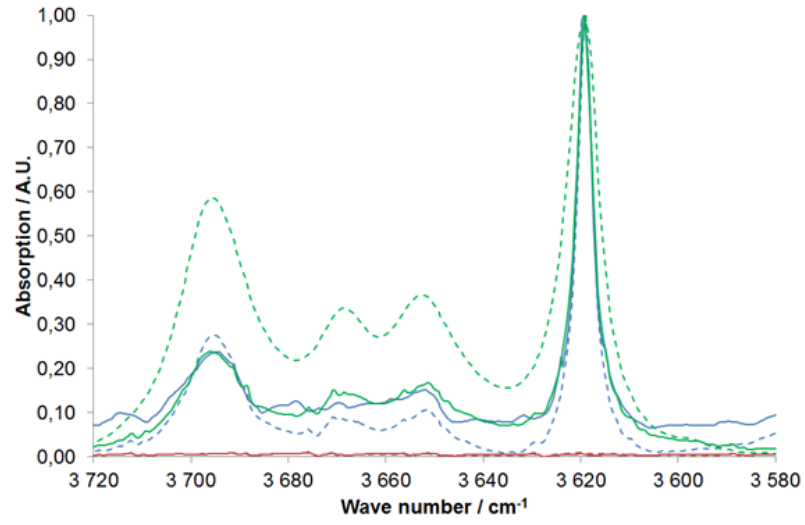

Fig 3 - FTIR spectra showing the important peaks (normalized) for the kaolin orientation, the spectra is baseline adjusted. Peak assignment, see Table 2. The red solid line $\mathrm{PVOH}_{\mathrm{t}=4.4}(-)$, red dotted line $\mathrm{PVOH}_{\mathrm{t}=10.9}\left({ }^{\cdots}\right)$, blue solid line PVOHk5.8t=5.2(-), blue dotted line PVOHk5.8t=11.1 ( ' $)$, green solid line PVOHk38 ${ }_{\mathrm{t}=5.9}(-)$ and green dotted line PVOHk38t=10.7 ( ' ).

Table 2 - The FTIR peak assignment and corresponding vibration modes for the studied peaks.

\begin{tabular}{l|l}
\hline $\begin{array}{l}\text { Wave number } \\
\mathbf{c m}^{-1}\end{array}$ & $\begin{array}{l}\text { Vibration mode (Farmer 1964, Peppas } \\
\text { 1977, Elton, Gate et al. 1999, Kozlov, } \\
\text { Quarmyne et al. 2003, Cole 2008) }\end{array}$ \\
\hline 3695 (kaolin) & $\begin{array}{l}\text { Dipole oscillation in OH perpendicular } \\
\text { to basal plane }\end{array}$ \\
3670 (kaolin) & Dipole oscillation in OH intra-layer \\
3652 (kaolin) & Dipole oscillation in OH intra-layer \\
3620 (kaolin) & Dipole oscillation in OH intra-layer \\
1142 (PVOH) & C-O stretch in crystalline region \\
1127 (kaolin) & Si-O stretch \\
1115 (kaolin) & Si-O stretch \\
1096 (PVOH) & C-O stretch in amorphous region \\
\hline
\end{tabular}

Table 1 also indicates a slightly decrease of $\kappa$ for the thinner barrier coatings, up to $5.8 \mathrm{wt} \%$, followed by an increase. The thicker barrier shows an increase of $\kappa$. This indicates that the orientation is affected by the thickness and the kaolin concentration. Upon the formation of the coatings with the rod, a rather small shear force is used, and the shear force is influenced by the thickness and kaolin content. Higher kaolin content can disturb the shear force action that otherwise would align the particles. The orientation is more random in the coatings with a lower kaolin load, whereas the kaolin platelets are forced to orient more in the layer for the thinner coatings, Table 1 column 5. Another factor that could influence the mass transport process is the degree of exfoliation of the clay particles, where the exfoliated clay particles are suggested to delay the transport of gas molecules through their capturing capacity (molecular sieves) (Pannirselvam et al. 2008). However, this was not addressed in this study and the used experimental conditions are not likely to have induced differences in the analysed materials that could explain the observed mass transport behaviour

Fig 4 shows the vibrations for the crystalline $\mathrm{PVOH}$ polymer in the $1140-1145 \mathrm{~cm}^{-1}$ region and the amorphous PVOH polymer in the region $1090-1096 \mathrm{~cm}^{-1}$ for some barriers (PVOH, PVOHk5.8 and PVOHk38) (Peppas

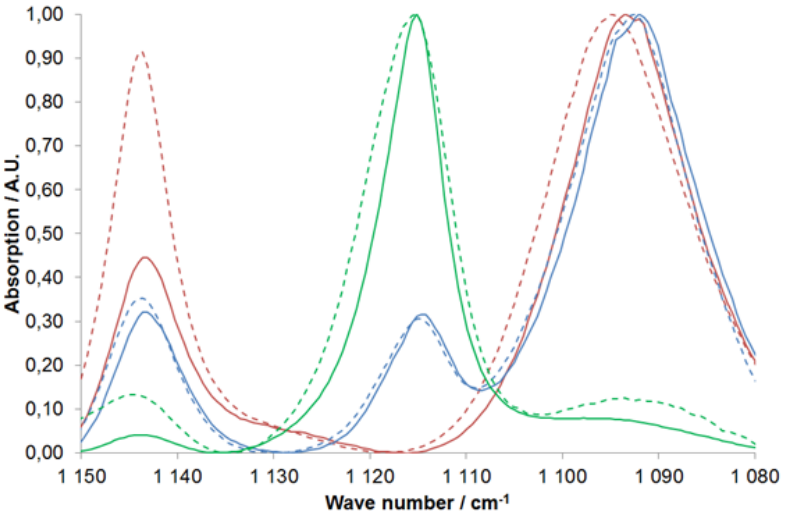

Fig 4 - FTIR spectra of the normalized peaks related to the crystalline and amorphous regions of $\mathrm{PVOH}$ and kaolin peaks, the spectra is baseline adjusted. Peak assignment, see Table 2. The red solid line $\mathrm{PVOH}_{\mathrm{t}=4.4}(-)$, , red dotted line $\mathrm{PVOH}_{\mathrm{t}=10.9}(\cdots)$, blue solid line PVOHk5.8t=5.2 (-), , blue dotted line PVOHk5.8t=11.1 ( ') , green solid line PVOHk38t=5.9 (-) and green dotted line PVOHk38t=10.7 ( ') .

1977, Kozlov et al. 2003). The peak around $1115 \mathrm{~cm}^{-1}$ is related to the $\mathrm{Si}-\mathrm{O}$ vibration in kaolin (Cole 2008). The PVOHk38, which has the highest kaolin content, has the highest peak around $1115 \mathrm{~cm}^{-1}$. The peak in the 1140 $1145 \mathrm{~cm}^{-1}$ region is decreasing with increasing kaolin content. The shift of the vibration for the crystalline and amorphous PVOH polymer seen in Fig 4 depends on the degree of crystallinity (Kozlov et al. 2003, Tretinnikov, Zagorskaya 2012), which was taken into account when calculating, $\alpha$, presented in Table 1. For $\mathrm{PVOH}$, the highest $\alpha$ was observed in the pure PVOH coatings for the thicker barrier, for the thinner barrier the highest crystallinity was obtained for $0.7 \mathrm{wt} \%$. Fig 4 shows the normalized peaks in the studied region.

The degree of crystallinity can be one reason why the oxygen mass transport time is different (Mogri, Paul 2001). The polymer layer nearest to the clay particles can be more crystalline and thereby transports oxygen differently compared to the rest of the matrix, (Furuheim et al. 2004). Small amounts of kaolin decrease the degree of crystallinity and increasing kaolin content increases the degree of crystallinity as determined from IR spectra. The PVOH in this article is semi-crystalline, meaning that there are regions in the sample where the polymer is well-ordered and close-packed (Solovyov, Goldman 2008), while other areas are amorphous. The location of the crystalline regions could not be determined in this study. However, since the crystallinity decreases as the kaolin content decreases, the starting point for crystalline ordering of the polymer might not be at the surfaces of the clay particles, but rather related to the consolidation and drying process (Wong et al. 2007).

The PVOH structure consists of a hydrocarbon backbone with single bonds, which means that the chains are rather flexible in accommodating for the diffusion of oxygen. In addition, the diffusion process is affected by the crystallinity, as well as the orientation and size of the crystalline regions. The crystalline regions have a similar effect as impermeable particles such as clay, forcing the oxygen molecules to take a torturous pathway (Solovyov, Goldman 2008). In order to analyze the crystallinity 
effect on the barrier properties, free volume measurements are needed, which merits for further investigation (Dhawan et al. 2014). Molecular simulation of the oxygen diffusion in PVOH has shown that the oxygen displacement preferentially happens along the backbone (Karlsson et al. 2004).

The crystalline regions can trap oxygen molecules for a certain time and thereby the lag time can be affected. The lag time for oxygen is related to the free volume and chain movements (Takeuchi 1990). Tightly packed chains with locally high alignment, such as crystalline regions, will reduce the diffusion of oxygen even if the free volume remains the same (Takeuchi et al. 1990).

The thick coatings that contained kaolin had a slightly lower $\alpha$ than the coatings which contained only $\mathrm{PVOH}$. The $\mathrm{PVOH}_{\mathrm{t}=10.9}$ coating had a lower $\alpha$ than the $\mathrm{PVOH}_{\mathrm{t}=4.4}$, which is probably due to the drying process. This was also observed for the barrier coatings with kaolin. In the thick coating, the polymer chains have a longer time to orient as water evaporates slower during the employed mild drying conditions (low temperature and only evaporative drying). The thicker barrier might have higher free volume and porosity, which can affect the drying of the barrier, this merit for further studies. The drying process is slightly different and also affected by the kaolin content, probably due to the differences in viscosity, and since the clay can hinder water diffusion. The clay in the polymer matrix can have an effect on the polymer crystallinity, as it has been shown that the clay induces crystalline regions near the clay platelets (Strawhecker, Manias 2000, Tang, Alavi 2011). This might explain for the observed strong increase in permeability with higher loading level of kaolin that also showed a higher degree of crystallinity for the thick films.

Water has a plasticizing effect on the $\mathrm{PVOH}$ polymer matrix. In other polymer matrices, such as amylose and starch, it has been shown that humidity can induce phase changes in the material (Stading et al. 2001, Masclaux et al. 2010). The water molecules diffuse mainly through the amorphous regions and attach to the hydroxyl side group of $\mathrm{PVOH}$, and can dissolve the crystalline regions at ambient temperature (Hodge et al. 1996). This disturbs both inter-molecular hydrogen bonding and causes swelling. In the present study, all measurements were performed at $50 \% \mathrm{RH}$, and the plasticizing effects can be different because of the thicknesses of films as well as the clay content. Furthermore, the water content in the sample can also influence the diffusion, since higher water contents will give a more fluid-like diffusion (Karlsson et al. 2004). Here the effect of water content on the coatings was not studied even if it is likely to play a role and will therefore be considered for future studies.

The SEM images of thin and thick barrier coatings are presented in Fig 5a-c and Fig 5d-f, respectively. Fig $5 a$ and Fig 5d show PVOH, Fig $5 b$ and Fig $5 e$ show PVOHk5.8, Fig 5c and Fig $5 f$ show PVOHk38. The SEM images of pure PVOH (Fig $5 a$ and $5 d$ ) show a dense and relatively smooth film, whereas the other coatings exhibit greater thickness variation and heterogeneous appearance as the kaolin concentration is increased.

The kaolin platelets are thin and have different lengths and their preferable orientation is in the basal plane of the coating. The SEM images of thin and thick coatings with the same kaolin content show that the kaolin is more aligned in the layer direction. For the thin samples the space is more confined, which forces the longer platelets to orient in the layer, see also Table 1 column 5. The shorter platelets, having a greater degree of freedom, orient more easily with an angle to the basal plane of the barrier.

The tortuosity for oxygen increased with increasing amount of kaolin, which also has been shown by others (Nielsen 1967, Solovyov, Goldman 2008). In addition, a small amount of kaolin decreased the crystallinity, while higher kaolin content led to a slightly higher crystallinity of the polymer, which in turn also resulted in higher tortuosity. It has been suggested that the tortuosity can improve the barrier properties by a factor of 10 or more (Lape et al. 2002). The tortuosity is dependent on the thickness of the kaolin platelets. For thinner kaolin platelets, the tortuosity is higher than for the thicker platelets. The effective pathway of the oxygen molecules is less affected by the thicknesses of the kaolin platelets, although the tortuosity is important for the pathway. This is consistent with the FTIR results regarding kaolin orientation, Table 1. This calls for future research regarding the tortuosity induced by the kaolin platelets and the crystalline regions. The kaolin content affects the morphology of the coatings.
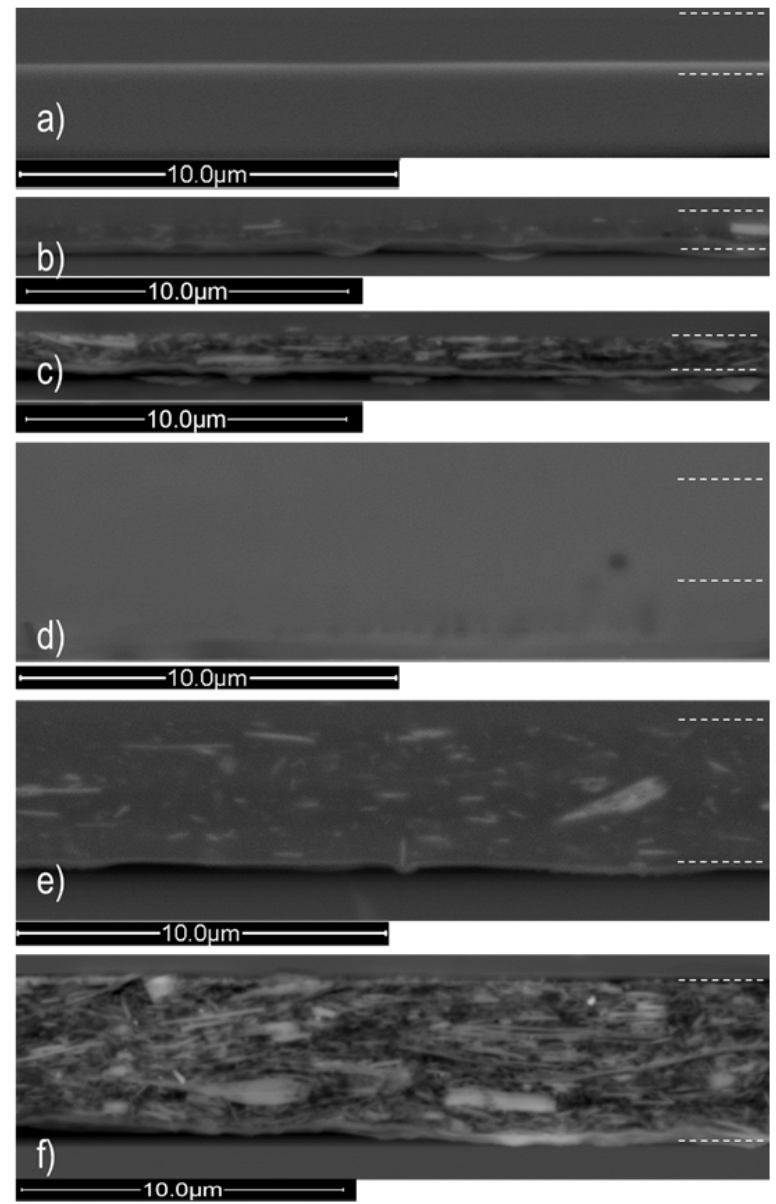

Fig 5 - Cross-section SEM micrographs of thin (a-c) and thick barrier (d-f) films containing a) and d) only $\mathrm{PVOH}$, b) and e) PVOHk5.8, c) and f) PVOHk38. The dashed line indicates the barrier coatings. Note the different scale bars. 


\section{Conclusions}

In this paper, different dispersion barriers containing polyvinyl alcohol, PVOH, and kaolin have been studied to gain understanding of how permeability is influenced by chemical and physical structure. Two different methods, oxygen transmission rate (OTR) and ambient ingress rate (AOIR), have been used to measure the oxygen permeability. The two methods showed similar results at steady state. The steady-state permeability is influenced by the thickness of the coating. The dynamic mass transport reveals additional information on how the structure influences the process, thickness and degree of crystallinity, also kaolin loading and kaolin orientation have an impact. It was shown that both the orientation of kaolin and the crystallinity of the polymer matrix influenced the permeability and dynamic mass transport. The effect of increased tortuosity and thus decreased permeability produced by the addition of kaolin to the coating was observed. Additionally, it was observed that an increased amount of kaolin led to decreased crystallinity.

Furthermore, an interesting feature was observed in the dynamics of the mass transport process. Thinner layers (with low kaolin content) could have higher early-stage permeability, but the steady-state values were higher for the thicker layers in the long run. The crystallinity and orientation of kaolin are not enough to describe the findings of these permeability. The reason for this behavior is not fully understood and merits further investigation.

The kaolin content affects the morphology of the coatings. The PVOH with low kaolin addition (up to $5.8 \mathrm{wt} \%$ ) has better barrier properties compared to the other barrier coatings.

\section{Acknowledgements}

This study was performed as part of the multidisciplinary Industrial Graduate School VIPP (www.kau.se/en/vipp) - Values Created in Fibre Based Processes and Products - at Karlstad University, with the financial support of the Knowledge Foundation, Sweden and Stora Enso.

At Stora Enso, the following persons are acknowledged for their assistance; MSc. Nina Miikki and MSc. Riitta Koivistolainen for the SEM images, MSc. Annika Kvist for support on FTIR, MSc. Elsa Klinga for support on Ox-Tran. Gratitude is also extended to Dr. Hanne Larsen of NOFIMA for tips on how to improve the PermMate measurement cells.

\section{Literature}

Bollström, R., R. Nyqvist, J. Preston, P. Salminen and M. Toivakka (2013): Barrier properties created by dispersion coating, Tappi J. 12(4), 45-51.

Cabedo, L. S., E. Giménez, J. M. Lagaron, R. Gavara and J. J. Saura (2004): Development of EVOH-kaolinite nanocomposites, Polymer 45(15), 5233-5238.

Cole, K. C. (2008): Use of infrared spectroscopy to characterize clay intercalation and exfoliation in polymer nanocomposites, Macromolecules 41(3): 834-843.

Crank, J. (1979): The mathematics of diffusion, Oxford: Clarendon Press, 1979 Paperback ed.
Dhawan, S., C. Varney, G. V. Barbosa-Cánovas, J. Tang, F. Selim and S. S. Sablani (2014): Pressure-assisted thermal sterilization effects on gas barrier, morphological, and free volume properties of multilayer EVOH films, J. Food Eng. 128(0), 40-45.

Elton, N. J., L. F. Gate and J. J. Hooper (1999): Texture and orientation of kaolin in coatings, Clay Miner. 34(1), 89-98.

Farmer, V. C. (1964): Infrared absorption of hydroxyl groups in kaolinite, Science 145(3637), 1189-1190.

Furuheim, K. M., D. E. Axelson, H. W. Antonsen and T. Helle (2004): Phase structural analyses of polyethylene extrusion coatings on high-density papers. I. Monoclinic crystallinity, J. Appl. Polym. Sci. 91(1): 218.

Gaume, J., C. Taviot-Gueho, S. Cros, A. Rivaton, S. Thérias and J. L. Gardette (2012): Optimization of PVA clay nanocomposite for ultra-barrier multilayer encapsulation of organic solar cells, Sol. Energy Mater. Sol. Cells, 99, 240-249.

Hodge, R. M., G. H. Edward and G. P. Simon (1996): Water absorption and states of water in semicrystalline poly(vinyl alcohol) films, Polymer 37(8), 1371-1376.

Huis in't Veld, J. H. J. (1996): Microbial and biochemical spoilage of foods: an overview, Int. J. Food Microbiol. 33(1), 118.

Johansson, C., J. Bras, I. Mondragon, P. Nechita, D. Plackett, P. Simon, D. G. Svetec, S. Virtanen, M. G. Baschetti, C. Breen, F. Clegg and S. Aucejo (2012). Renewable Fibers and Bio-Based Materials for Packaging Applications - a Review of Recent Developments, BioResources 7(2), 2506-2552.

Johansson, C. and F. Clegg (2015). Hydrophobically modified poly(vinyl alcohol) and bentonite nanocomposites thereof: Barrier, mechanical, and aesthetic properties, J. Appl. Polym. Sci. 132(13)

Karlsson, G. E., U. W. Gedde and M. S. Hedenqvist (2004). Molecular dynamics simulation of oxygen diffusion in dry and water-containing poly(vinyl alcohol), Polymer 45(11): 38933900.

Kozlov, M., M. Quarmyne, W. Chen and T. J. McCarthy (2003): Adsorption of poly(vinyl alcohol) onto hydrophobic substrates. A general approach for hydrophilizing and chemically activating surfaces, Macromolecules 36(16), 60546059.

Lape, N. K., C. F. Yang and E. L. Cussler (2002): Flake-filled reactive membranes, J. Membr. Sci. 209(1), 271-282.

Larsen, H., A. Kohler and E. M. Magnus (2000): Ambient oxygen ingress rate method - an alternative method to Ox-Tran for measuring oxygen transmission rate of whole packages, Packaging Technology and Science 13(6), 233-241.

Lee, L.-H. (1968): Relationships between surface wettability and glass temperatures of high polymers, J. Appl. Polym. Sci. 12(4): 719-730.

Lopez-Cervantes, J., D. I. Sanchez-Machado, S. Pastorelli, R. Rijk and P. Paseiro-Losada (2003): Evaluating the migration of ingredients from active packaging and development of dedicated methods: a study of two iron-based oxygen absorbers, Food Addit. Contam. 20(3), 291-299. 
Masclaux, C., F. Gouanve and E. Espuche (2010): Experimental and modelling studies of transport in starch nanocomposite films as affected by relative humidity, J. Membr. Sci. 363(1-2), 221-231.

Mogri, Z. and D. R. Paul (2001): Gas sorption and transport in side-chain crystalline and molten poly(octadecyl acrylate), Polymer 42(6), 2531-2542.

Moldrup, P., T. Olesen, T. Komatsu, P. Schjønning and D. E. Rolston (2001): Tortuosity, diffusivity, and permeability in the soil liquid and gaseous phases, Soil Sci. Soc. Am. J. 65(3), 613-623.

Nielsen, L. E. (1967): Models for the permeability of filled polymer systems, J. Macromol. Sci. - Chemistry, A1(5), 929942.

Pannirselvam, M., A. Genovese, M. C. Jollands, S. N. Bhattacharya and R. A. Shanks (2008): Oxygen barrier property of polypropylene-polyether treated clay nanocomposite, eXPRESS Polym. Lett. 2(6), 429-439.

Peppas, N. A. (1977): Infrared spectroscopy of semicrystalline poly(vinyl alcohol) networks, Die Makromolekulare Chemie 178(2), 595-601.

Sanchez-Garcia, M. D., A. Lopez-Rubio and J. M. Lagaron (2010): Natural micro and nanobiocomposites with enhanced barrier properties and novel functionalities for food biopackaging applications, Trends Food Sci. Technol. 21(11), 528-536.

Sapalidis, A. A., F. K. Katsaros, T. A. Steriotis and N. K. Kanellopoulos (2012): Properties of poly(vinyl alcohol)Bentonite clay nanocomposite films in relation to polymer-clay interactions, J. Appl. Polym. Sci. 123(3), 1812-1821.

Solovyov, S. and A. Goldman (2008): Mass transport and Reactive Barriers in Packaging: Theory, Applications and Design, DEStech Publications, Inc.
Stading, M., A. Rindlav-Westling and P. Gatenholm (2001): Humidity-induced structural transitions in amylose and amylopectin films, Carbohydr. Polym. 45(3): 209-217.

Strawhecker, K. E. and E. Manias (2000): Structure and properties of poly(vinyl alcohol)/Na+ montmorillonite nanocomposites, Chem. of Mater. 12(10), 2943-2949.

Takeuchi, H. (1990): A Jump Motion of Small Molecules in Glassy-Polymers - a Molecular-Dynamics Simulation, The Journal of Chemical Physics 93(3), 2062-2067.

Takeuchi, H., R. J. Roe and J. E. Mark (1990): Molecular dynamics simulation of diffusion of small molecules in polymers. II. Effect of free volume distribution, The Journal of Chemical Physics 93(12), 9042-9048.

Tang, X. Z. and S. Alavi (2011): Recent advances in starch, polyvinyl alcohol based polymer blends, nanocomposites and their biodegradability, Carbohydr. Polym. 85(1), 7-16.

Tretinnikov, O. N. and S. A. Zagorskaya (2012): Determination of the degree of crystallinity of poly(vinyl alcohol) by FTIR spectroscopy, J. Appl. Spectrosc. 79(4), 521-526.

Wong, S. S., S. A. Altinkaya and S. K. Mallapragada (2007): Crystallization of poly(vinyl alcohol) during solvent removal: Infrared characterization and mathematical modeling, J. Polym. Sci. Part B: Polymer Physics 45(8): 930-935.

Yu, Y. H., C. Y. Lin, J. M. Yeh and W. H. Lin (2003): Preparation and properties of poly(vinyl alcohol)-clay nanocomposite materials, Polymer 44(12), 3553-3560.

Zehetmeyer, G., R. M. D. Soares, A. Brandelli, R. S. Mauler and R. V. B. Oliveira (2012): Evaluation of polypropylene/montmorillonite nanocomposites as food packaging material, Polym. Bull. 68(8), 2199-2217.

Manuscript received April 21, 2015 Accepted July, 1, 201 